\title{
Distribution Optimization of Constrained Damping Materials Covering on Typical Panels Under Random Vibration
}

\author{
Shuangyan Liu, Yihang Xu, Xiaopeng Shi, Qiong Deng and Yulong Li \\ Fundamental Science on Aircraft Structural Mechanics and Strength Laboratory, Northwestern Poly-technical \\ University, Xian 710072, Shaanxi, PR China.
}

\section{(Received 5 August 2016; accepted 2 March 2018)}

This paper studies topology optimization of metallic and composite panels of three different configurations (flat, three-bay and $3 \times 3$ grid) covered by the constrained damping materials considering first modal loss factors. The vibration experiments seek to obtain the first modal loss factor and first modal frequency for the aforementioned panels, and corresponding finite element (FE) simulations are completed using commercial software ABAQUS ${ }^{\circledR}$. According to simulation results, the distribution of constrained damping materials is optimized with evolutionary structural optimization (ESO) method developed using MATLAB. The results show that the first modal loss factors of optimized panels are reduced slightly if the constrained damping material is removed by 50\%. Under the base excitation near each first modal frequency, the maximum root mean square of Von Mises equivalent stress (RMISES) of optimized flat panels and $3 \times 3$ grid stiffened panels decreases compared with panels without constrained damping materials. However, the maximum RMISES value of optimized three-bay stiffened panels nearly remains unchanged due to the configuration type of the stiffeners. These results conclude that the three-bay stiffened panel is the best to reduce the maximum RMISES value of at base structure with the same additional mass.

\section{INTRODUCTION}

The control of resonance vibration of structures has always been a fundamental concern in aerospace, automobiles, and other industries ${ }^{1-4}$ on topics of noise reduction and increasing service life. There are application studies on various structures, including helicopter blades, ${ }^{2}$ pilot seats on aircrafts, ${ }^{3}$ and connections to cockpit floors. ${ }^{4}$ An effective way to control vibration is covering passively-constrained damping material on the surface of violently vibrating structures. Although this method is simple, with reasonable distribution, it can provide high damping effects over a wide range of frequency and temperature ${ }^{5}$ without significantly altering structural mass or stiffness. Numerous papers have been published in the past decades on the vibration damping analysis of full-coverage constrained damping material treatment. ${ }^{2-4,6-9}$ However, full coverage treatment is impractical due to added excessive mass to base structures. Therefore, topology optimization of damping materials with partial-coverage treatment is widely used where only a portion of the base structure is covered with constrained damping material. Generally, many optimization methods were adopted to optimize locations of the patches on base structures. For example, the modified gradient method, ${ }^{10}$ the Genetic Algorithm (GA) method, ${ }^{11}$ the Method of Moving Asymptote (MMA), ${ }^{12}$ and the evolutionary structural optimization (ESO) method ${ }^{13-18}$ were used to find optimal locations of constrained damping patches which will maximize the modal damping ratio of the structures. In most published work on partial coverage damping treatment, it has been emphasized that attention must be given to the frequency and damping properties of optimization treatment effects on the structure. For example, Kang et al. ${ }^{19}$ investigated damping layer optimization in shell structures under periodic excitation to minimize the structural vibration level. The complex mode superposition method in conjunction with the state space approach - which could deal with non-proportional damping to calculate the steady state response of the vibrating structure. However, the study was only focused on flat panel and shell, not on stiffened panels. Based on this, Zhang et al. ${ }^{20}$ proposed the integrated topology optimization of host structures and damping layers to reduce vibration levels in the presence of harmonic excitations. During the optimization process, the localized modes in low-density areas were avoided. The analysis method applied validity only in flat panel and the hollow cylinder shell structure, not in complicated structures. Takezawa et al. ${ }^{21}$ carried out a new objective function to optimize damping layers for reduce resonance. In the proposed objective function, the optimization problem was formulated to maximize the complex part of the proposed complex dynamic compliance under a volume constraint. This optimization program was used in 2D/3D beam structures. Khalfi, et al. ${ }^{22}$ presented a parametric study of partial constraining layer damping (PCLD) characteristics on the responses of a rectangular plate. The obvious suppressing vibration effects were obtained by optimization. However, there are two points that have not been discussed: 1) the optimized structure only related to the simple flat panel or shell, not stiffened panels, and 2) the fatigue life of optimized structures has been rarely investigated under random vibration, even though full-scale fatigue testing for Aerospace application of metal and composite constructions have been investigated ${ }^{23,24}$ in recent years. Reasoning can be attributed to the idea that most of optimization studies about constrained damping treatment on base structures aim to suppress vibration which is mainly characterized by damping loss factor, and that in random vibration, the fatigue life is sta- 


\begin{tabular}{l}
\hline \hline Table 1. Material properties of aluminum alloy 2024 and butyl rubber. \\
\begin{tabular}{|c|c|c|c|c|}
\hline Material & $\rho\left(\mathrm{kg} / \mathrm{m}^{3}\right)$ & $\mathrm{E}(\mathrm{MPa})$ & $\nu$ & Thickness $(\mathrm{mm})$ \\
\hline Al2024 & 2780 & 70000 & 0.346 & 1.8 \\
\hline Butyl rubber & 1300 & 8 & 0.48 & 0.5 \\
\hline
\end{tabular}
\end{tabular}

tistical without consistent repetition in repeated experiments. In recent years, the root mean square of von Mises equivalent stress (RMISES) ${ }^{25-27}$ was widely used to characterize fatigue life. When the RMISES value reaches maximum, the structure might crack first at the corresponding point, which accounts for the critical point.

While, most available literature is related to metal panels, in recent years composite panels, especially thin-walled stiffened panels, are widely used in many industries. Detailed studies on damping effects of partially-covered constrained damping materials on composite panels are rarely investigated. Therefore, in this paper, the modal frequency, modal loss factor, and RMISES of optimized partial constrained damping materials covering typical panels are discussed under random vibration. The related typical panels were made of two materials widely used in industries: the aluminum alloy 2024 and carbon composite T700/8256. ESO method was adopted for its simplicity and robustness to maximize the first modal loss factor. The main content includes three parts: first, simple vibration experiments were carried out to obtain the first modal loss factor and the first modal frequency of the samples and the corresponding FEM models were built. Next, the ESO method was adopted based on the above mentioned FEM models to optimize constrained damping material distributions of the metal flat panel, metal three-bay stiffened panel, and metal $3 \times 3$ grid stiffened panel. At the same time, similar optimization distribution of the composite panels with the same dimensions is investigated based on the ESO method. Finally, the modal loss factor and the RMISES of metal and composite panels are studied.

\section{EXPERIMENTAL AND NUMERICAL VALIDATION}

\subsection{Experiments}

In order to obtain the modal loss factor and first modal frequency of the simple structure, vibration tests of the metallic flat panel with or without partial-coverage constrained damping materials are carried out. The corresponding samples are labeled as $1 \#$ and $2 \#$, respectively. Figure 1 shows the dimensions of sample $2 \#$. The metallic flat panel, damping layer, and constrained layer are made of aluminum alloy 2024, butyl rubber, and unidirectional carbon fiber composite laminate with layout $0_{6} 6$ along the long side respectively. The butyl rubber is provided by Beijing Aerospace Materials and Technology Research Institute (BAMTRI). The carbon fiber laminate is fabricated by curing unidirectional resin-based carbon fiber prepreg USN10000 at $120^{\circ} \mathrm{C}$ for 2 hours, which is provided by Weihai Guangwei composites Co., Ltd. The loss factor values of damping material and carbon factor composite laminate are 1.0 and 0.012 within the frequency range from 180 to $210 \mathrm{~Hz}$, respectively. They are obtained by a dynamic thermo-mechanical analysis (DMA) test at room temperature by shear mode and three-point bending mode. The material properties of the metal flat panel, butyl rubber, and carbon fiber lamina are listed in Table 1, and Table 2.
Table 2. Material properties of unidirectional carbon fiber lamina.

\begin{tabular}{|c|c|c|c|c|c|}
\hline $\begin{array}{c}\rho \\
\left(\mathrm{kg} / \mathrm{m}^{3}\right)\end{array}$ & $\begin{array}{c}\mathrm{E} 11 \\
(\mathrm{GPa})\end{array}$ & $\begin{array}{c}\mathrm{E} 22 \\
(\mathrm{GPa})\end{array}$ & $\begin{array}{c}\mathrm{G} 12 \\
(\mathrm{GPa})\end{array}$ & $\nu$ & $\begin{array}{c}\text { Thickness } \\
(\mathrm{mm})\end{array}$ \\
\hline 1635 & 125 & 10.3 & 4.3 & 0.29 & 1.12 \\
\hline
\end{tabular}

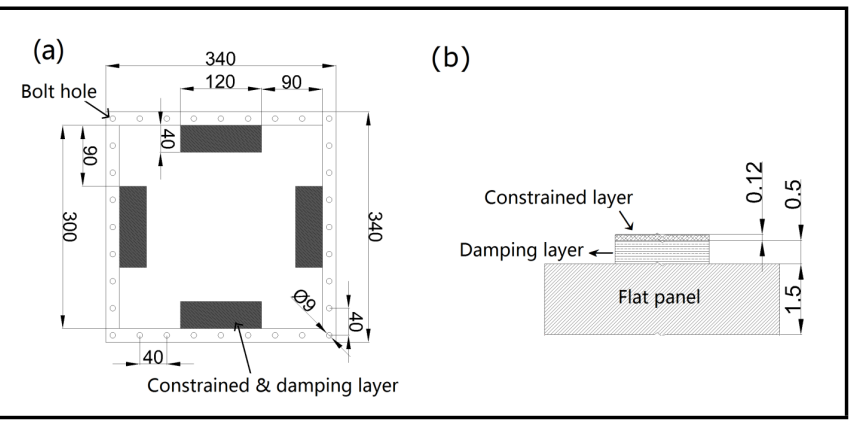

Figure 1. The dimensions of sample 2: (a) position and dimension of the constrained damping materials and (b) layout and thickness of the constrained damping materials.

The samples are fixed at the vibration shaker using bolted cover-plate during vibration experiment, and the assembly and testing arrangement of sample $2 \#$ is shown in Fig. 2 (a). The vibration shaker, bolt, cover-plate, and constrained and damping layers have been specified in Fig. 2 (a). Based on the sine wave sweep method by the electro-dynamic shaker, the frequency, and modal damping ratio are measured by half-power bandwidth. The sweep speed is $5 \mathrm{~Hz} / \mathrm{min}$ and the sweep ranges are 0.8-1.2 times of each sample's nature frequencies. Laser displacement sensor is used to record the vibration amplitude signals history in the center of the sample. The vibration response curve in the frequency domain is obtained by Fast Fourier Transformation (FFT) from the time-domain response data. The frequency at the first peak of voltage is the first modal frequency $\left(f_{1}\right)$. The modal loss factor $(1)$ is computed by the half-power bandwidth method. Using this method, the first modal frequency and modal loss factor of samples $1 \#$ and 2\# are obtained.

\subsection{Numerical Simulations}

Numerical simulations are carried out to illustrate the vibration experiments. The FEM model is shown in Fig. 2 (b) with a global mesh size of $5 \mathrm{~mm}$. The panel and damping layer are isotropic and therefore modelled by quad-dominated S4R and C3D8R elements in ABAQUS ${ }^{\circledR}$, respectively. The constrained layer is laminated and modelled by S4R elements. The dimensions of both samples $1 \#$ and $2 \#$ are shown in Fig. 2 (a) and for simulations - the holes for bolted connections are ig-

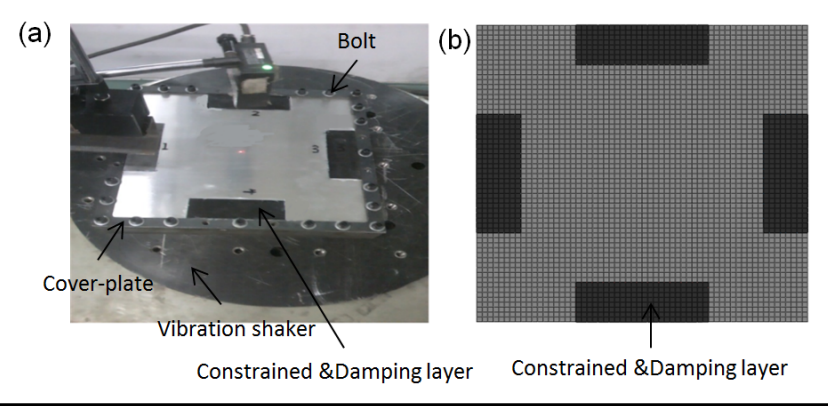

Figure 2. Sample 2 with partial coverage constrained damping material: (a) experimental set-up (b) FE model with a mesh size of $5 \mathrm{~mm}$. 
Table 3. The first modal frequency and modal loss factor of the metallic flat panel sample.

\begin{tabular}{||c|c|c|c|c||}
\hline \multirow{2}{*}{} & \multicolumn{2}{|c|}{$1 \#$} & \multicolumn{2}{c|}{$2 \#$} \\
\cline { 2 - 5 } & $f_{1}(\mathrm{~Hz})$ & $\eta_{1}(\%)$ & $f_{1}(\mathrm{~Hz})$ & $\eta_{1}(\%)$ \\
\hline Experiment values & 184.33 & 0.65 & 210.88 & 1.2377 \\
\hline Simulation values & 184.67 & - & 204.20 & 1.1871 \\
\hline
\end{tabular}

nored for simplicity. The panel, the damping core, and the constrained layer are tied in the model. Fixed boundary conditions are applied around the metallic panel edges. The analysis step in commercial software ABAQUS ${ }^{\circledR}$ is frequency. The modal loss factor of the sample $2 \#$ is computed by modal strain energy method. The corresponding formula is shown as ${ }^{24}$

$$
\eta_{k}=\frac{\eta_{d} E_{d k}+\eta_{c} E_{c k}+\eta_{b} E_{b k}}{E_{s k}}
$$

where $\eta_{k}$ is the $k^{t h}$ order modal loss factor of the structure; $\eta_{c}$, $\eta_{d}$ and $\eta_{b}$ are the loss factors of the constrained material layer, damping material layer, and base structure, respectively; $E_{c k}$, $E_{d k}, E_{b k}$ are the $k^{t h}$ order modal strain energy of constrained material layer, damping material layer, and base structure, respectively; and $E_{s k}$ is the total strain energy of all the structural elements in the $k^{\text {th }}$ mode.

\subsection{Simulation Validation}

The first modal loss factors $\left(\eta_{1}\right)$ and frequencies $\left(f_{1}\right)$ of sample $1 \#$ and $2 \#$ obtained by the experiment and simulation are presented in Table 3.

As shown in Table 3, the difference in the first modal frequency of sample 1 \# between the simulation and the experiment is about $1 \%$, demonstrating that the simulation results have a good agreement with the experiments and the numerical results could reproduce some vibration characters in the experiment. The first modal loss factor of sample 2 \# was obtained by Eq. 1 in the simulation. In the simulation of sample $2 \#$, the modal loss factor of base panel equals to that of sample $1 \#$ measured by the experiment. For sample 2\#, the differences are about $4 \%$ both in the first modal frequency and modal loss factor. The reason is that the thicknesses of the damping layer and constrained layer in numerical simulation are not fully equal to those in the experiment because the cured process was manually carried out at room temperature. Generally, the first modal frequency and the first modal loss factor of the structure obtained by the simulations are nearly the same as those by the experiments, which suggest that our numerical simulation set-up is nearly accurate. Thus, the distribution optimization of constrained damping materials on three different panels is carried out based on this numerical model.

\section{DISTRIBUTION OPTIMIZATION OF TYPICAL STIFFENED PANELS}

\subsection{ESO Method}

ESO method is a discrete variable method which uses binary decision to remove the unnecessary part. In the present study, the damping core and corresponding constrained layer element are assigned as a design variable $\left(x_{i}\right)$. Without the element, design variable value would be set to 0 ; otherwise, the variable value would be set to 1 . The constraint is reducing $50 \%$ mass of the constrained damping material with the aim to maximize the structural first modal loss factor.

The procedures for the topology optimization of the structure with constrained damping materials implemented in MATLAB are outlined as follows:

(1) Build a finite element model by ABAQUS code and output the modal strain energy of each element after analysis.

(2) Compute the modal loss factor $\eta_{1}$ using Eq. 1 coded in C program.

(3) Determine the sensitivity of the $i^{\text {th }}$ design variable, $S_{k i}$ by the following formulation: ${ }^{28}$

$$
\begin{gathered}
s_{k i}=\frac{\eta_{d}}{E_{s k}}\left[\frac{\left(E_{d k i}+E_{d k i}^{\prime}\right) E_{d k}}{E_{s k}}-E_{d k i}\right] ; \\
s_{i}=\sum_{k=1}^{N} w_{k} \frac{s_{k i}}{\left|s_{k i}^{\text {max }}\right|} ; \\
\sum_{k=1}^{N} w_{k}=1 \quad \text { and } w_{k}>0, k=1,2, \ldots, N ;
\end{gathered}
$$

where $s_{k i}$ is the sensitivity of modal loss factor of the $i^{\text {th }}$ damping material element in $k^{\text {th }}$ mode; $s_{i}$ is the sensitivity of modal loss factor of the $i^{\text {th }}$ damping material element in the first $\mathrm{N}$ modes; $w_{k}$ is the weight coefficient in the $k^{\text {th }}$ mode; $E_{d k i}$ is the modal strain energy of the $i^{\text {th }}$ damping material element in the $k^{\text {th }}$ mode; $E_{d k i}^{\prime}$ is the modal strain energy of the $i^{\text {th }}$ constrained material element in the $k^{\text {th }}$ modal.

The scheme of sensitivity filtering ${ }^{29}$ is used to modify the original sensitivity value as

$$
s_{i}^{\text {new }}=\frac{1}{x_{i} \sum_{i=1}^{N} H_{i}} \sum_{j=1}^{N} H_{j} x_{j} s_{j} .
$$

Although topology optimization has been widely used, there are still some shortcomings such as checker board patterns and mesh-dependency. To overcome these limitations, the discrete mesh filtering technique is adopted, and the original sensitivity values are modified based on a weighted average of the design variable sensitivities in a fixed neighborhood. The convolution operator $H_{i}{ }^{28}$ is written as

$$
H_{i}=\max (0, r-\operatorname{dist}(i, j))
$$

where the operator $\operatorname{dist}(i, j)$ is defined as the distance between the center of element $i$ and the center of element $j$. The convolution operator $H_{i}$ is zero outside the filter size $r$.

(4) Gradually remove the elements with maximum sensitivity values after filtering.

(5) Repeat step 1 to step 4, until the mass of constrained damping material reaches the maximum restriction value.

\subsection{Optimal Distributions of Typical Stiffened Panels}

In this paper, ESO method is used for obtaining the optimal distributions of constrained damping material on typical stiffened panels and the flat panel which is a reference panel. The stiffened panels include three-bay stiffened panel and $3 \times 3$ grid stiffened panel. In the following optimization, metal stiffened 
Table 4. Material property of 3M112D.

\begin{tabular}{||c|c|c|c|c||}
\hline Temperature $\left({ }^{\circ} \mathrm{C}\right)$ & $\rho\left(\mathrm{kg} / \mathrm{m}^{3}\right)$ & $\mathrm{E}(\mathrm{MPa})$ & $\nu$ & $\eta$ \\
\hline 30 & 980 & 10 & 0.499 & 1 \\
\hline
\end{tabular}
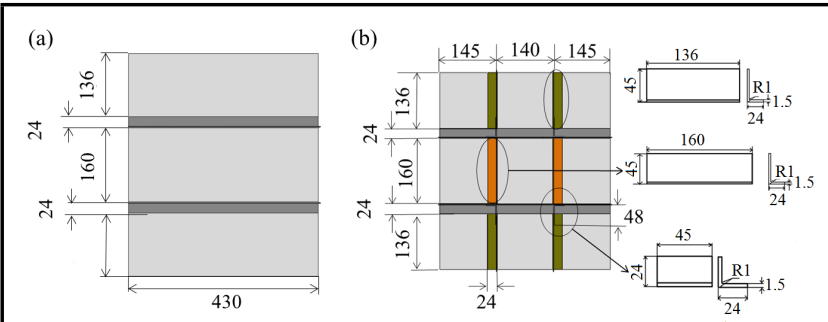

Figure 3. The sketches of (a) the three-bay stiffened panel and (b) the $3 \times 3$ stiffened panel. Note: The dimension unit is $\mathrm{mm}$ and $R 1=1 \mathrm{~mm}$.

panels and carbon fiber composite stiffened panels are investigated. For the metal stiffened panels, the material of three panels is aluminum alloy 2024, unidirectional resin-based glass fiber laminates with layout $0_{2}$ are adopted as the constrained layer, and the viscoelastic material 112D from 3M Company is employed as the damping core. In case of composite stiffened panels, the material of stiffened panels is carbon fiber composite T700/8256 with the layout $0 /(0 / 45 / 90 /-45)_{3} / 0_{2}$, unidirectional carbon fiber composite laminates with layout $\mathrm{O}_{2}$ are adopted as the constrained layer, and the same viscoelastic material is employed as the damping core in metal-stiffened panels. The thickness of each fiber layer is $0.1 \mathrm{~mm}$.

The mechanical properties of the metallic panels are shown in Table 1. Material properties of viscoelastic material 3M112D, unidirectional glass fiber laminates and carbon fiber composite T700/8256 are listed in Table 4 and Table 5, respectively. All the base panels are of the same dimensions of $430 \mathrm{~mm} \times 480 \mathrm{~mm} \times 1.5 \mathrm{~mm}$. The thickness of the damping core and the constrained layer is $1.0 \mathrm{~mm}$ and $0.2 \mathrm{~mm}$, respectively. The detail sketches of the three-bay stiffened panel and the $3 \times 3$ grid stiffened panel are shown in Fig. 3 .

All the FE simulation models follow the modelling technique mentioned in section 2.2 of this paper. The damping core layer is modelled by C3D8R elements while the other parts are modelled by S4R elements with the same mesh size of $5 \mathrm{~mm}$, respectively. The panels, the damping core, and the constrained layer are tied in the models. The modal strain energy of each element is output to a specified file, and the modal damping factor are computed based on modal strain energy method. The optimization process is conducted as mentioned in section 3.1. In this paper, the filter size (r) is 50 during the sensitivity filtering process and the number of removal elements is set as 100 in every loop.

\subsection{Stress Distribution Effects for Opti- mized Panels}

Stress distribution of vibrating panels might be changed significantly after optimization, which considerably affects the fatigue life of panels under resonance. Therefore, it is necessary to investigate the stress distribution of the panels before and after optimization under resonance. In random vibration, the loading is nondeterministic, and the response can be characterized only in a statistical sense. The root mean square of von Mises equivalent stress ${ }^{26}$ (RMISES) is a statistical variable and it is the function of frequency and node position. Therefore, the

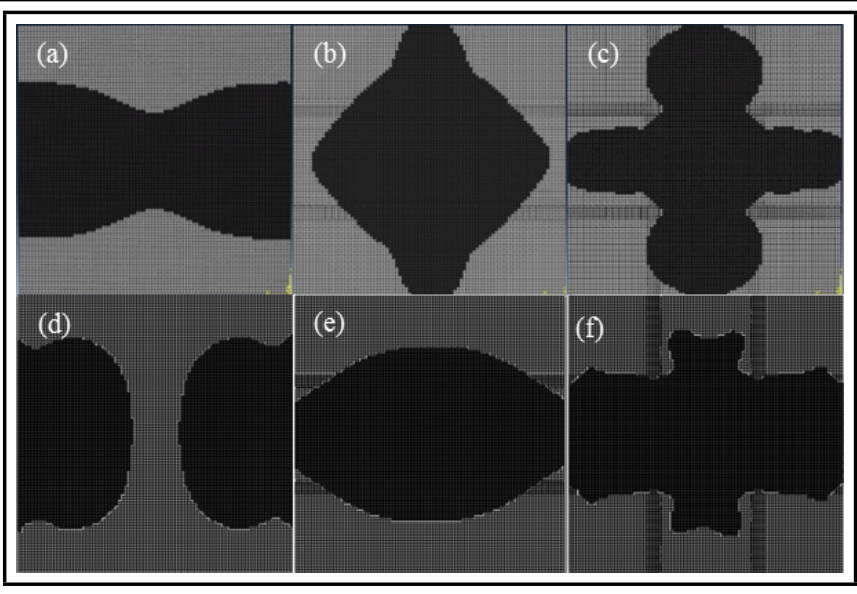

Figure 4. The optimal distributions of constrained damping material covering (a) metallic flat panel, (b) metallic three-bay stiffened panel, (c) metallic $3 \times 3$ grid stiffened panel,(d) composite flat panel,(e) composite three-bay stiffened panel, and (f) composite $33 \times 33$ grid stiffened panel.

RMISES distribution of the specified frequency always characterizes the stress distribution of structures, and the maximum RMISES value always characterizes the fatigue life in random vibratio. $^{27}$

In the present study, the optimized panels include the flat panel, three-bay stiffened panel, and $3 \times 3$ grid stiffened panel. They are excited by base motion with the amplitude of PSD $3.54 \mathrm{~g}^{2} / \mathrm{Hz}$, and the frequency value is 0.8 to 1.2 times of the panel's first modal frequencies. The original three panels with and without the full-coverage materials are studied at the same time as the reference. The analysis step is the random response for all the simulations.

\section{RESULTS AND DISTRIBUTIONS}

\subsection{Optimization Distribution and Damping Effect}

The optimal distributions of constrained damping material covering on metallic panels and composite panels are shown in Fig. 4. In these panels, the mass of constrained damping materials is removed by $50 \%$.

As is evident in Fig. 4(a)-(c), the different distributions of constrained damping material suggest that the stiffener configurations have a significant effect on the optimization results. Comparing Fig. 4(a) with Fig. 4(d), the different distributions of constrained damping material suggest that the materials of the base panels still play an important role in the optimization results. It should be mentioned that the anisotropy of composites is ignored in damping property but considered in the mechanical property. The damping property of the panels in the constrained damping layer is mainly decided by the shear effect on a damping layer. Therefore, the shear deformation plays an important role in the optimization distribution of constrained damping materials. As shown in Fig. 5 (a)-(f), there are significant differences in shear strain distribution among the panels, which lead to different optimization results shown in Fig. 4 (a)-(f).

In order to illustrate the effect of the optimal constrained damping materials distribution on different typical panels in detail, the first modal loss factors $\eta_{1}$ of metal and composite base structure versus removal ratios are shown in Fig. 6 (a). For 
Table 5. Material properties of unidirectional glass fiber laminates.

\begin{tabular}{||c|c|c|c|c|c|c|c|c||}
\hline Material & $\begin{array}{c}\text { Density } \\
\left(\mathrm{kg} / \mathrm{m}^{3}\right)\end{array}$ & $\begin{array}{c}\text { E1 } \\
(\mathrm{MPa})\end{array}$ & $\begin{array}{c}\mathrm{E} 2 \\
(\mathrm{MPa})\end{array}$ & $\begin{array}{c}\nu_{12} \\
(\mathrm{MPa})\end{array}$ & $\begin{array}{c}G_{12} \\
(\mathrm{MPa})\end{array}$ & $\begin{array}{c}G_{13} \\
(\mathrm{MPa})\end{array}$ & $\begin{array}{c}G_{23} \\
(\mathrm{MPa})\end{array}$ & $\eta$ \\
\hline UGFL & 1360 & 42000 & 9000 & 0.29 & 5300 & 5300 & 3500 & 0.012 \\
\hline T700/8256 & 1920 & 122500 & 8300 & 0.3 & 5000 & 5000 & 3160 & 0.012 \\
\hline
\end{tabular}

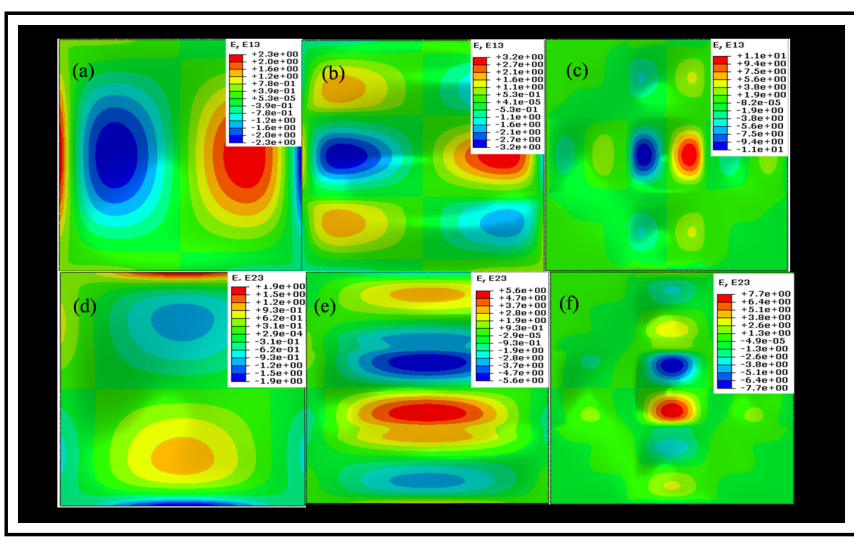

Figure 5. The shear strain distribution $e_{13}$ of damping layer on (a) metallic flat panel, (b) metallic three-bay stiffened panel, (c) metallic $3 \times 3$ grid stiffened panel; the shear strain distribution $e_{13}$ of damping layer on (d) metal flat panel, (e) metal three-bay stiffened panel, (f) metal $3 \times 3$ grid stiffened panel

simplicity, the first modal damping factor values of the metal and composite panels without constrained damping materials are taken as $0.5 \%$ and $1.2 \%$ in this paper.

As shown in Fig. 6 (a), the first modal loss factors of composite panels are higher than those of corresponding metallic panels. The reason is that with the same damping material, the damping loss factors of the composite base structures are higher. When the removal ratio varies from 0 to $50 \%$ for the metallic flat panel and three-bay stiffened panel configurations, the first modal loss factor values of these metallic panels decrease by $20 \%$ and $28 \%$, respectively.

In case of composite panels - flat and three-bay stiffened - for the same removal ratio, the first modal loss factor values decrease by about $15 \%$ and $19 \%$, respectively. The results showed that with half of the constrained damping materials removed, the first modal loss factors of flat panel and three-bay stiffened panel decreased far less than $50 \%$. The reason for this decrease is that the removed elements have a very little contribution to strain energy dissipation in the first modal shape and the corresponding sensitivity values are always negative during the optimization. However, for the $3 \times 3$ grid stiffened panel, the first modal loss factor in metal and composite panels increases by $7 \%$ and $28 \%$, respectively. The reason for this increase is that, unlike other panels, the removed elements have a negative contribution to strain energy dissipation and the corresponding sensitively values are positive.

When the removal ratio varies from $50 \%$ to $100 \%$, the first modal loss factor values of the optimized metallic flat panel, metallic three-bay stiffened panel, and metallic $3 \times 3$ grid stiffened panel are 13.8, 7.6, and 5.8 times of those without constrained damping material, respectively. Similarly, the first modal loss factor values for the optimized composite flat panel, composite three-bay stiffened panel, and composite $3 \times 3$ grid stiffened panel are 10.5, 7.5, and 7.1 times of those without constrained damping material, respectively.

Generally, when the removal ratio varies from 0 to $50 \%$, the first modal loss factors of flat panel, three-bay stiffened panel, and $3 \times 3$ grid stiffened panel decrease far less than $50 \%$. Par- (a)

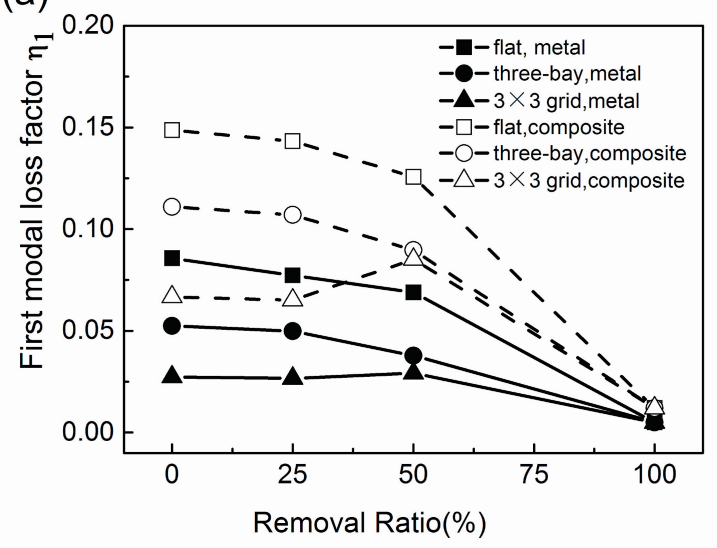

(b)

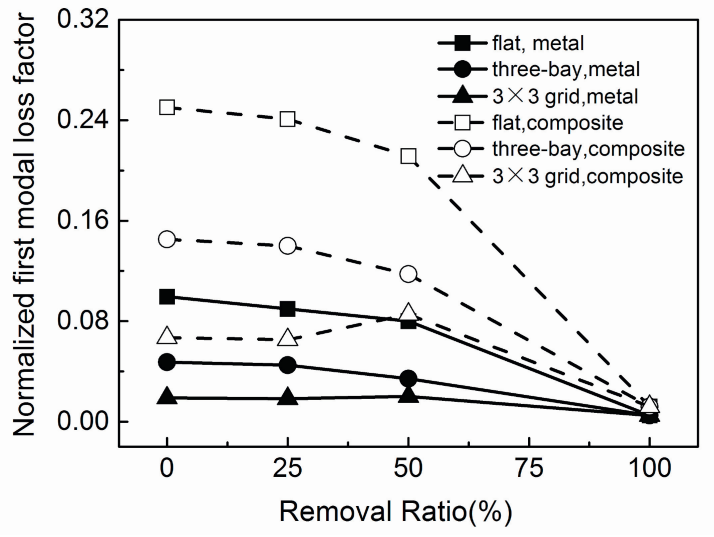

Figure 6. The (a) first modal loss factors and (b) normalized first modal loss factors of six panels versus removal ratio.

ticularly for $3 \times 3$ grid stiffened panel, this factor even increases gradually. When the removal ratio varies from $50 \%$ to $100 \%$, the first modal loss factors of all the panels increase significantly. This phenomenon indicates that the constrained damping material after optimization has very good performance in reducing mass and suppressing vibration.

Among metallic panels, the first modal loss factor of the $3 \times 3$ grid stiffened panel is the least. The first possible reason is that the strain energy of base structure in the $3 \times 3$ grid stiffened panel is larger compared with other metal panels; the second is that the $3 \times 3$ grid stiffeners make the shear strain of damping layer more even and the strain energy of damping layer is less than the metal flat panels and three-bay stiffened panels, as shown in Fig. 5 (c). A similar phenomenon is observed in composite $3 \times 3$ grid stiffened panels.

The additional mass has important effects on the structural stiffness. Therefore, in order to exclude the effect of the additional mass difference in optimization, the first modal loss factor of each panel is normalized by the total mass of the corresponding base structures as shown in Fig. 6 (b). Comparing Fig. 6 (a) to Fig. 6 (b), the trend lines of three panels vary slightly which implies that additional mass has little effect on the modal loss factor of panels in the optimization process. 


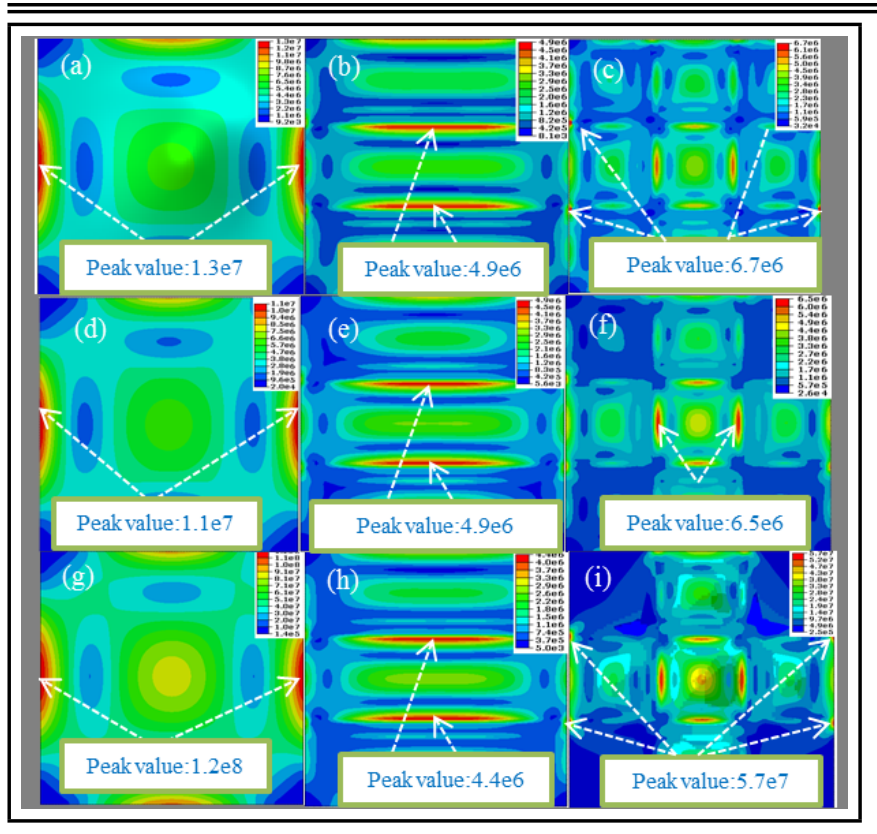

Figure 7. The RMISES distribution of metallic flat panels including (a), (d), and (g); metallic three-bay stiffened panels including (b), (e) and (h); and metallic $3 \times 3$ grid stiffened panels including (c), (f), and (i). Images (a), (b) and (c), illustrate the removal ratio of $0 \%$; (d), (e) and (f) represent the removal ratio of $50 \%$; (g), (h) and (i) show the removal ratio of $100 \%$.

\subsection{Stress Distribution Effects of Optimized Panels under Random Vibration}

The RMISES contours at the first modal frequency of the three metallic panels and three composite panel configurations with constrained damping material removal ratios of 0 , $50 \%$, and $100 \%$ of constrained damping materials are shown in Fig. 7 and Fig. 8, respectively.

As shown in Fig. 7 (a), (d) and (g), the RMISES distribution of the flat panel remains unchanged while the peak value of the RMISES changes significantly as the removal ratio varies, which indicates that the additional constrained damping materials have little effect on the RMISES distribution while it has a distinct effect on the maximum RMISES value. The similar results are found in the three-bay stiffened panel as shown in the middle column of Fig. 7. However, as shown in the right column of Fig. 7, for the removal ratio of 50\%, the peak RMISES value of $3 \times 3$ grid stiffened panel appears in the center area while the peak values of the other two appear around the edges where the stiffeners tied to the panels as shown in Fig. 7 (c) and (i). The reasons are that the distribution of optimized constrained damping materials on the center area of the metal panel and the $3 \times 3$ grid stiffeners aggravate the stress convergence.

Figure 8 shows, as the removal ratio changes, RMISES peak value, the location of RMISES peak value and the RMISES distribution might change for composite flat panels, three-bay stiffened panels and $3 \times 3$ grid stiffened panels. Different from the metallic flat panel at removal ratio $100 \%$, the corresponding RMISES distributions and peak values of composite flatpanel change significantly. The reason is that the material of metal flat panel is isotropic, while that of composite one is anisotropic. Similar results are observed in both the three-bay stiffened panel and $3 \times 3$ grid stiffened panel. For the composite $3 \times 3$ grid stiffened panel, the RMISES distribution nearly remains unchanged while the peak value of the RMISES changes

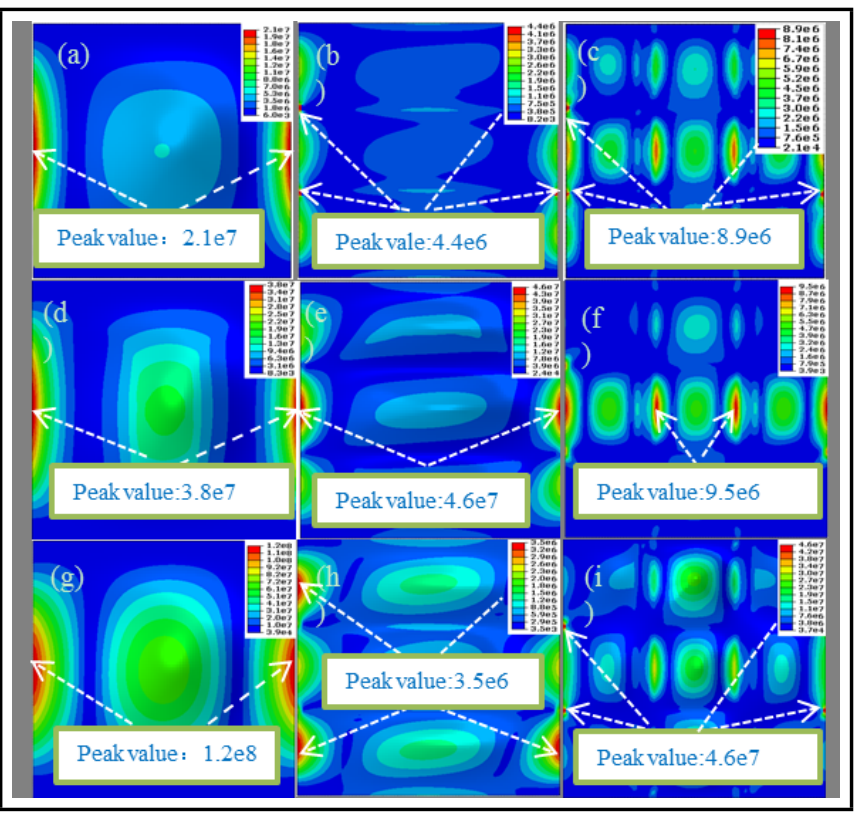

Figure 8. The RMISES distribution of composite flat panels at their first modal frequency including (a), (d), and (g); three-bay stiffened panels including (b), (e) and (h); and $3 \times 3$ grid stiffened panels including (c), (f), and (i). Images (a), (b), and (c), illustrate the removal ratio of $0 \%$; (d), (e) and (f) represent the removal ratio of $50 \% ;(\mathrm{g}),(\mathrm{h})$, and (i) show the removal ratio of $100 \%$.

significantly, as shown in Fig. 8 (c) and (i). After optimization, the corresponding RIMISES distribution and peak value change obviously, as shown in Fig. 8 (f). The reason is that the constrained damping materials tied on the composite $3 \times 3$ grid stiffened panel add the local mass concentration, which changes the mass distribution of origin structures.

In order to illustrate the effect of damping performance and the stiffeners configuration on maximum RMISES value of the panels at the first modal frequency in detail, the RMISES peak value and modal loss factor of three metal and composite panels varying with the removal ratio are drawn in Fig. 9 (a) and Fig. 9 (b), respectively.

It can be seen in Fig. 9 (a), with the removal ratio from 0 to $50 \%$, the maximum RMISES value of metallic flat panel changed slightly. However, with the removal ratio from $50 \%$ to $100 \%$, the maximum RMISES value of metal flat panel increased nearly 10 times. This indicates that the optimal structure is more economical and effective in controlling resonance vibration. The similar result can be found in the $3 \times 3$ grid stiffened panel. Comparing Fig. 9 (a) with Fig. 9 (b), the same trends are observed in the composite flat panel and $3 \times 3$ grid stiffened panel. Generally, the maximum RMISES values markedly decrease after constrained damping treatments while the first modal loss factors increase in flat and three-bay stiffened panels. However, the maximum RMISES values of the panels are not associated with the first modal loss factors of the corresponding panels when the removal ratio changes. The reason is that the first modal loss factor shows the ability of energy dissipated of the whole structure, however, the maximum RMISES values character structures local stress in random vibration. Only when the first modal loss factor varies significantly and stress distribution of the base structure is even does the first modal loss factor have a negative correlation with the maximum RMISES value of the panels.

However, whether the metal or composite base structure, the varieties of the maximum RMISES values for three-bay 


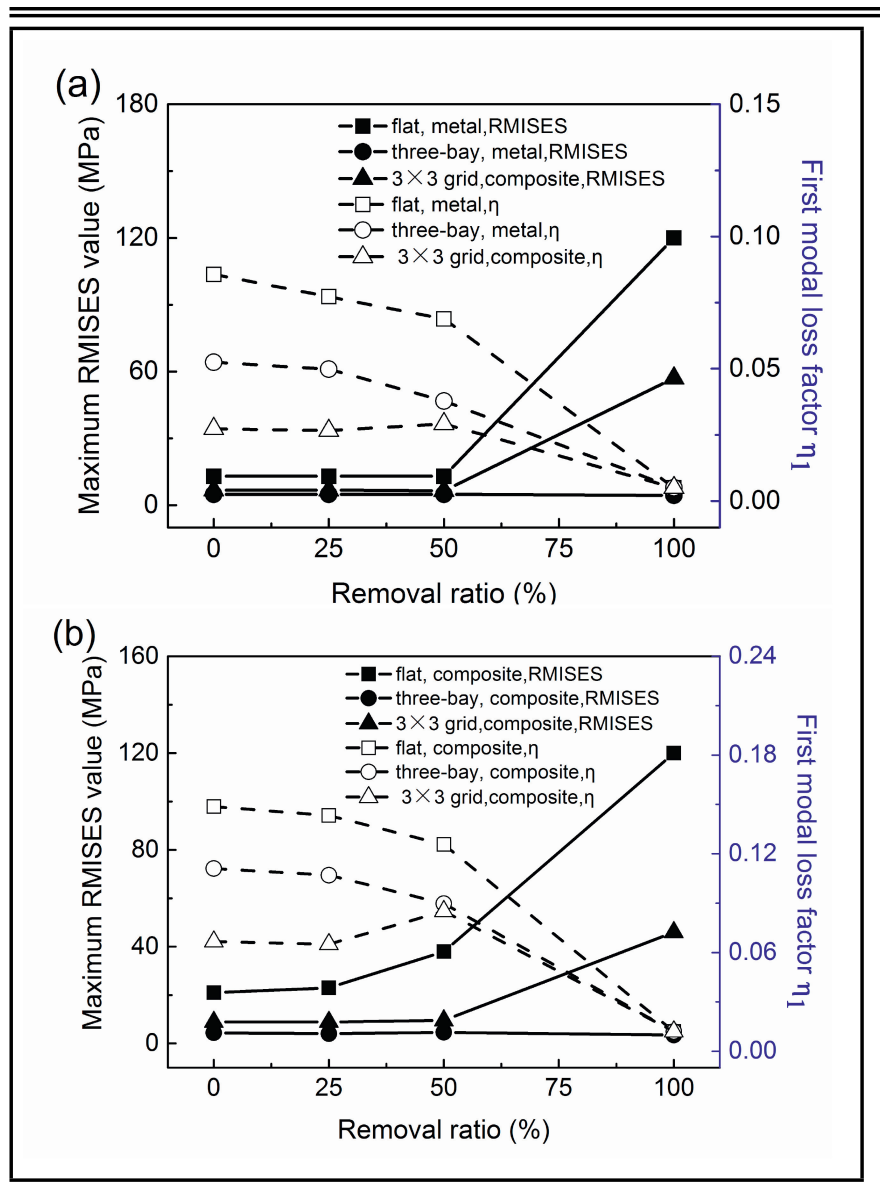

Figure 9. Graphical representations of Maximum RMISES values and the first modal loss factors of metallic panels and composite panels. Graph (a) shows original results while (b) depicts a variation in the removal ratio.

stiffened panels are significantly different from those of flat panel and $3 \times 3$ grid stiffened panel as the removal ratio varies. When the removal ratio varies from 0 to $100 \%$, the maximum RMISES values of three-bay stiffened panel nearly remained unchanged even if the corresponding modal loss factors vary significantly. This result implies that the configuration type of the stiffeners plays an important role in the maximum RMISES value of the panels.

It is evident in Fig. 9 (a) and Fig. 9 (b), for both metal and composite base structures, the maximal RMISES values of the flat panels are the largest while those of three-bay stiffened panels are smallest in all the panels. The three-bay stiffeners tied to the substrates make the concentration of the stress distributed, which makes the maximum RMISES value decrease sharply. Comparing $3 \times 3$ grid stiffened with three-bay stiffened panels, more stiffeners increase the local strength and local stress concentration. Generally, the maximum RMISES values of three-bay stiffened panels are the smallest compared with others at the same removal ratio. It can be concluded that stiffener configures of three-bay stiffened panel is the best one to decrease the maximum RMISES value of the base structure with the same additional mass.

\subsection{CONCLUSIONS}

In this paper, metallic and carbon-fiber composite typical panels of three different configurations with constrained damping material treatment were optimized using ESO method with the aim of maximizing the first modal loss factor of panels when constrained damping material is removed by $50 \%$. The stress analysis of optimized metal and composite panels at the first modal frequency during random vibration were conducted. Several conclusions were obtained as follows:

(1) The first modal loss factors of optimized metallic and composite panels decrease far less than $50 \%$ with the removal ratio of $50 \%$. The results suggest that optimized panels have good performance in suppressing vibration with light weight.

(2) The optimized constrained damping materials distribution varies with different panels. The reason is that distinctness of the stiffener configures and material properties of panels lead to significant differences in shear strain distribution of panels.

(3) Under base excitation near each first modal frequency, the additional constrained damping materials have little effect on the RMISES distribution while they have a distinct effect on the maximum RMISES value. The reason is that the first modal loss factor shows the ability of energy dissipated of the whole structure, and its value indirectly expresses reduction in the stress value of the whole structure. However, the maximum RMISES values character structures local stress in random vibration. Only when the first modal loss factor varies significantly and stress distribution of the base structure is even for example, full-coverage constrained damping materials on panels - does the first modal loss factor have a negative correlation with the maximum RMISES value of the panels.

(4) The configuration type of the stiffeners might play an important role in the maximum RMISES value of the panels. For example, in both metallic and composite panels, the maximum RMISES value of the flat panel is the largest while that of three-bay stiffened panel is the smallest at removal ratio of $100 \%$. Stiffener configures of three-bay stiffened panel is the best one to decrease the maximum RMISES value of the base structure with the same additional mass.

\section{AKNOWLEDGEMENTS}

We thank Tao Li and Sheikh Muhammad Zakir for help in paper revision and this work is supported by National Natural Science Foundation of China (grant No. 11272267, and 11102168) and the 111 project (No. B07050).

\section{REFERENCES}

1 Xiang, J., Yan, Y., Li, D. Recent advance in nonlinear aeroelastic analysis and control of the aircraft, Chinese Journal of Aeronautics, 27 (1), 12-22, (2014). https://dx.doi.org/10.1016/j.cja.2013.12.009

2 Rasuo, B. Experimental study of structural damping of composite helicopter blades with different cores, Plastics Rubber \& Composites, 39 (1), 1-5 (2010). https://dx.doi.org/10.1179/174328910X12608851832092

3 Ilic, Z., et al. Potential connections of cockpit floor seat on passive vibration reduction at a piston propelled airplane, Technical Gazette, 21 (3), 471-478, (2014). https://dx.doi.org/10.17559/TV

4 Ilic, Z., et al. The efficiency of passive vibration damping on the pilot seat of piston propeller aircraft, Measurement, 95, 21-32, (2017). https://dx.doi.org/10.1016/j.measurement.2016.09.042 
${ }^{5}$ Kim, S.Y., Mechefske, C.K., Kim, I.Y. Optimal damping layout in a shell structure using topology optimization, Journal of Sound and Vibration, 332 (12), 2873-2883, (2013). https://dx.doi.org/10.1016/j.jsv.2013.01.029

${ }^{6}$ Rao, D.K. Frequency and loss factors of sandwich beams under various boundary conditions, International Journal of Mechanical Engineering Science, 20, 271-278, (1978). https://dx.doi.org/10.1243/JMES_JOUR_1978_020_047_02

7 Yan, M.J., Dowell, E.H. Governing equations of vibrating constrained layer damping sandwich plates and beams, Journal of Applied Mechanics, 94, 1041-1047, (1972). https://dx.doi.org/10.1115/1.3422825

${ }^{8} \mathrm{He}$, J.F., Ma, B.A. Analysis of flexural vibration of viscoelastically damped sandwich plates, Journal of Sound and Vibration, 126, 37-47, (1988). https://dx.doi.org/10.1016/0022-460X(88)90396-3

9 Johnson, C.D., Kienholz, D.A. Finite element prediction of damping in structures with constrained viscoelastic layers, AIAA Journal, 20 (9), 1284-1290, (1982). https://dx.doi.org/10.2514/6.1981-486

10 Alvelid, M. Optimal position and shape of applied damping material, Journal of Sound and Vibration, 310 (4-5), 94765, (2008). https://dx.doi.org/10.1016/j.jsv.2007.08.024

11 Zuo, S.G., Wei, K.J. Multi-objective Optimization of a Multi-chamber Perforated Muffler Using an Approximate Model and Genetic Algorithm, International Journal of Acoustics and Vibration, 21 (2), 152-163, (2016). https://dx.doi.org/10.20855/ijav.2016.21.2405

12 Ling, Z., Ronglu, X., Yi, W., El-Sabbagh, A. Topology optimization of constrained layer damping on plates using Method of Moving Asymptote (MMA) approach, Shock and Vibration, 18 (1), 221-244, (2011). https://dx.doi.org/10.3233/SAV-2010-0583

${ }^{13}$ Guo, Z., Chen, Y., Hou, Q. Topology optimization in damping structure based on ESO, Journal of China Ordnance, 4, 293-298, (2008).https://dx.doi.org/10.3969/j.issn.10012354.2006.10.002

${ }^{14}$ Huang, X., Xie, Y.M. A new look at the ESO/BESO optimization methods, Structural and Multidisciplinary Optimization, 35 (1), 89-92, (2008). https://dx.doi.org/10.1007/s00158-007-0140-4

15 Huang, X., Xie, Y.M. A further review of ESO type methods for topology optimization, Structural and Multidisciplinary Optimization, 41 (5), 671-683, (2010). https://dx.doi.org/10.1007/s00158-010-0487-9

${ }^{16}$ Huang, X., Xie, Y.M. . Bi-directional evolutionary topology optimization of continuum structures with one or multiple materials, Computational Mechanics, 43 (3), 393-401, (2009). https://dx.doi.org/10.1007/s00466-008-0312-0

17 Zheng, J., Long, S.Y., Li, G.Y. The topology optimization design for continuum structures based on the element free Galerkin method. Engineering Analysis with Boundary Elements, Engineering Analysis with Boundary Elements, 34, 666-672, (2010). https://dx.doi.org/10.1016/j.enganabound.2010.03.001
${ }^{18}$ Rozvany, G., Querin, O.M. Combining ESO with rigorous optimality criteria, International Journal of Vehicle Design, 28, 294-299, (2002). https://dx.doi.org/10.1504/IJVD.2002.001991

19 Kang, Z., Zhang, X., Jiang, S., Cheng, G. On topology optimization of damping layer in shell structures under harmonic excitations, Structural and Multidisciplinary Optimization, 46 (1), 51-67, (2012). https://dx.doi.org/10.1007/s00158-011-0746-4

${ }^{20}$ Zhang, X., Kang, Z. . Vibration suppression using integrated topology optimization of hoststructrues and damping layers, Journal of Vibration and al Control, 22 (1), 60-76, (2016). https://dx.doi.org/10.1177/1077546314528368

21 Takezawa, A., Daifuku, M., Nakano, Y., Nakagawa, K., Yamamoto, T., Kitamura, M. Topology optimization of damping material for reducing resonance response based on complex dynamic compliance, Journal of Sound and Vibration, 365, 230-243, (2016). https://dx.doi.org/10.1016/j.jsv.2015.11.045

${ }^{22}$ Khalfi, B., Ross, A. Transient and harmonic response of a sandwich with partial constrained layer damping: A parametric study, Composites Part B: Engineering, 91, 44-55, (2016). https://dx.doi.org/10.1016/j.compositesb.2015.12.037

${ }^{23}$ Rasuo, B. Experimental Techniques for Evaluation of Fatigue Characteristics of Laminated Constructions from Composite Materials: Full-Scale Testing of the Helicopter Rotor Blades, Journal of Testing and Evaluation (JTE), ASTM International, 39 (2), 237-242, (2011). https://dx.doi.org/10.1520/JTE102768

${ }^{24}$ Grbovic, A., Rasuo, B. FEM based fatigue crack growth predictions for spar of light aircraft under variable amplitude loading, Engineering Failure Analysis, 26, 50-64, (2012). https://dx.doi.org/10.1016/j.engfailanal.2012.07.003

${ }^{25}$ Lee, Y. L., Pan, J., Hathaway, R., Barkey, M. Fatigue testing and analysis: Theory and practice $[\mathrm{M}],(2005)$. https://dx.doi.org/10.1016/B978-0-7506-7719-6.50014-2

26 Segalman, D.J., Fulcher, C.W.G., Reese, G.M., Field Jr, R.V. An efficient method for calculating RMS von Mises stress in a random vibration environment, Journal of Sound and Vibration, 230 (2), 393-410(18), (1970). https://dx.doi.org/10.1006/jsvi.1999.2606

27 De la Fuente, E. Von Mises stresses in random vibration of linear structures, Computers \& Structures, 87 (21), 1253-1262, (2009). https://dx.doi.org/10.1016/j.compstruc.2009.06.008

${ }^{28}$ Sigmund, O. Numerical in stabilities in topology optimization: a survey on procedures dealing with checkerboard, mesh dependencies, local minima, Structural Optimization, 16 (1), 67-75, (1998). https://dx.doi.org/10.1007/BF01214002

${ }^{29}$ Bendsoe, M.P., Sigmund, O. Topology optimization: theory, methods and applications[M]: Springer Science \& Business Media, (2004). https://dx.doi.org/10.1007/978-3662-05086-6 